\title{
A new central configuration in the planar $N$-body problem
}

\author{
AGNIESZKA SILUSZYK
}

\section{ABSTRACT.}

B. Elmabsout [C. R. Acad. Sci. 329, Serie II (1991)] has proved that a central configuration of $2 n$ bodies located on two concentric regular $n$-gons exists iff the polygons are homotetic or similar with an angle equal to $\frac{\pi}{n}$ and the masses on the same polygon are equal. In this paper we study the existence of a planar central configuration which consists of $3 n$ bodies also situated on two regular polygons, the "interior" $n$-gon with equal masses and the "exterior" $2 n$-gon with masses of two quantities, and these quantities alternate.

\section{REFERENCES}

[1] Albouy, A., The symmetric central configurations of four equal masses, Contemp. Math., 198 (1996), 131-135

[2] Albouy, A. and Kaloshin, V. Finiteness of central configurations of five bodies in the plane, Annals of Mathematics, 176 (2012), No. 1, 535-588

[3] Arnold, V. I., Kozlov, V. V. and Neishtadt, A. I., Mathematical Aspects of Classical and Celestial Mechanics, Springer-Verlag, Berlin, 2006

[4] Elmabsout, B., Sur l'éxistence de certaines positions d'equilibre relatif dans le probléme des $n$ corps, Celest. Mech., 41 (1988), 131-151

[5] Elmabsout, B., Nouvelles configurations d'equilibre relatif pour le probléme des $N$ corps, C. R. Acad. Sci., 329, Serie II (1991), 467-472

[6] Grebenicov, E. A., Two new dynamical models in celestial mechanics, Rom. Astron. J. 8 (1998), No. 1, 13-19

[7] Grebenicov, E. A., Kozak-Skoworodkin, D. and Jakubiak, M., Methods of Computer Algebra in Many-Body Problem, Ed. of UFP, Moscow, (2002) (in Russian)

[8] Grebenicov, E. A. and Zemtsova, N. I., On the existence of asymmetric solutions of the functional LagrangeWintner's equations, Moscow, RAN, 70-78, (1999), (in Russian)

[9] Grebenicov, E. A. and Zemtsova, N. I., New central configurations in Newton 10-body problem, in: Proceedings of the 3rd International Conference on Actual Problems of Mechanics and Engineering, EVERO, Almaty, 2009, pp. 123-133

[10] Kozak-Superson, D., Numerical research of the stability domains for solutions of the restricted 14-body problem with incomplete symmetry, in: Computer Algebra Systems in Teaching and Research. Differential Equations, Dynamical Systems and Celestial Mechanics, Eds.: L.Gadomski [et all]. Siedlce, 2011, Published by Collegium Mazovia, 191-197

[11] Macmilian, W. D. and Bartky, W., Configurations in the problem of four bodies, Trans. Amer. Math. Soc., 34 (1932), 838-875

[12] Meyer, K. and Hall, G. R., Introduction to Hamiltonian Dynamical Systems and the N-Body Problem, New York, 1992

[13] Siluszyk, A., On the linear stability of relative equilibria in the restricted eight-body problem with partial symmetry, Vesnik Brestcaga Universiteta, 2 (2004), 20-26

[14] Wiliams, W. L., Configurations in the problem of five bodies, Trans. Amer. Math. Soc., 44 (1938), 562-579

[15] Wintner, A., The analytical foundations of celestial mechanics, Princeton University Press, 1941

\author{
SiedlCe University of NATURAL SCIENCES AND Humanities \\ FACULTY OF SCIENCES \\ KonARSKIEgo 2, 08-110, SiedlCE, PolAND \\ E-mail address: sil_a@uph.edu.pl
}

Received: 31.10.2013; In revised form: 09.09.2014; Accepted: 20.10.2014

2010 Mathematics Subject Classification. 70F10, 70F15.

Key words and phrases. $N$-body problem, planar central configurations . 